\title{
A Study on the Effects of Reciting on Chinese College Students' Oral English Proficiency
}

\author{
Xiao Liu \\ Inner Mongolia Finance and Economics College, Huhhot, China \\ Email: zhaoliu1116@163.com
}

\begin{abstract}
This paper aims to illuminate the relationship between reciting and the efficiency of English learning among Chinese college students. Through a series of experiments and tests, the research draws the conclusion that the traditional English learning strategy----reciting promotes the students' oral English proficiency.
\end{abstract}

Index Terms - reciting, oral English, proficiency, effectiveness, input and output

\section{INTRODUCTION}

Chinese college students have learned English for at least six years, but strangely enough, they can hardly communicate in English. They have accumulated much knowledge about English, but that does not guarantee the use of English. Is there a way to bridge the gap between what they have learned and what they can say? This paper aims to find out such an efficient way to help college students out of bafflement. This method is recitation. In order to testify the effects of reciting on college students' oral English, an experiment has been conducted. This experimental study aims to find out if reciting is really helpful in achieving college students' oral fluency. And to what degree and in what aspects it is helpful.

\section{THEORETICAL BACKGROUND}

\section{A. Production of Oral Speech}

Following Levelt (1989), speech production consists of four major stages: conceptualizing a thought to be expressed, formulating a linguistic plan, articulating the plan, and monitoring one's speech.

\section{B. Linguistic Input}

Input is the starting place for language acquisition. A natural language environment is the ideal setting for sufficient and efficient language input. Canadian immersion or exposure programs are of this kind. Many language researchers have proposed relevant theories on this respect. Rod Ellis (1985) holds that input refers to the language addressed to the L2 learner either by a native speaker or by another L2 learner. Interaction consists of the discourse jointly constructed by the learner and his illocutions; input, therefore, is the result of the interaction. Stephen Krashen (1987) argues the best methods are therefore those that supply 'comprehensible input' in low anxiety situations, containing messages that students really want to know. These methods do not force early production in the second language, but allow students to produce when they are ready, recognizing that improvement comes from supplying communicative and comprehensible input, and not from forcing and correcting production.

\section{Input and Output}

To the functions of learner's output on SLA, there are some controversial opinions. According to Krashen (1985), learners' output has no direct effect on acquisition. The skill building hypothesis states that we first learn rules or items consciously and then gradually atomize them through practice. The representative of this hypothesis is Swain. She argues that comprehension of language does not need close attention to its form, so enough input of linguistic materials does not automatically lead to the intake the language form. There are many learners who can be quick in understanding but slow in producing language. Swain's claim is that production will aid acquisition only when the learner is pushed into producing output that is concise, coherent and appropriate in order to develop full grammatical competence.

These are all hypothesis about the possible functions that input may play in SLA. Though no explicit conclusion have been drawn so far concerning input functions in SLA, the essential role of input is generally accepted. As to the specific effect of frequency, comprehensibility and output, further research is called for. Nevertheless, it is generally agreed that there is a positive correlation between the above mentioned three aspects and SLA.

\section{Inspiration to Chinese Learners}

Contrast with learners who can immerge in the language being studied, oral speech production is an easy task, for Chinese learners the production of oral speech is the most difficult and also the worst performed part in their learning 
process. What causes such big difference? Apart from the difficulties in speech organs to pronounce the intended sounds, another critical problem is the deficiency in language input, which contains three aspects: (1) the monotonousness in input style-written text. (2) the limitedness in input time-English class. (3) the finiteness in input processing- bottom up analyzing. Here, "bottom" refers to the basic linguistic units such as alphabetic letters, phonemes and syllables. The bottom up process proceeds from the smaller linguistic units to the larger parts, i.e., words, phrases, sentences and paragraphs. As a result of deficient linguistic input, the learner has not stored adequate linguistic information in their mind to meet the needs of spontaneous oral production. Here, one thing should be made clear, i.e., to know the Chinese translation of vocabularies does not guarantee the proper use of them, for an overall information of any vocabulary contains generally four concepts. They are phonology, morphology, syntax and sometimes pragmatics. Without a thorough mastery of all the related aspects, learners either find hesitant in using them in their speech or make errors in their attempt to take risks. Then in Chinese learning environment, is there a good solution to this problem? The answer is positive. That is to make good use of those input language materials. To be more specific, it is to process the material in a different way. In addition to the widely accepted bottom up practice, learners should go step further. On the one hand, they should familiarize themselves with the English pronunciation by practicing their speech organs. On the other hand, they should commit those vocabularies to memory by remembering them in their linguistic contexts, from the sentences and texts that they are used. Since these texts are explained in class with the teacher's help, they are comprehensible. According to the above mentioned input theories, comprehensible linguistic input is helpful to the learners, but it does not ensure intake. To promote intake, apart from increasing the input frequency, the more important task is to raise the learners' awareness of the gap between what they want to say to what they can say; and between what they said last time and the correct expressions they have just come across. Without real English speaking environment, the learners can practice speaking to themselves trying to remember as many correct expressions as possible. Then a practical and helpful way develops, which has been proved to be efficient by many learners. It is the reciting of English texts. In the reciting process, the learners must repeatedly read and till at last say the language materials with their speech organs, thus they can be ready to produce any words that they have practiced as accurately and quickly as possible. That is required in the third stage of oral speech production as have mentioned in the first part of the paper. At the same time, learners can learn the specific usage of words or expressions in their linguistic context. Or mostly they can combine the separated linguistic elements into chunks, which will be of great help both in storage and later retrieval, thus can largely reduce the time spent in the second stage of oral production.

\section{RESEARCH MethodOLOGY}

\section{A. Research Subjects}

The subjects of this study are 100 freshmen from two parallel classes in Inner Mongolian Finance and Economics College. They major in Tourism Management and Finance Engineering respectively. They are divided into two groups, the control group (20males, 30females) and the experimental group (26males, 24females). Both groups have attended the English proficiency test at the beginning of the semester. The statistical results show that the two groups have equivalent English proficiency level when they enter college $(\mathrm{p}=0.133>0.05)$. See table 1 for detailed information. The two groups study the same text book: New Horizon College English Book1, published by Foreign Language Teaching and Research Press. They are taught by the same English teacher in the same way and with the same learning class hours. The only difference is that after finishing each unit, the experimental group is required to recite some paragraphs selected carefully by the teacher while the control group does not.

TABLE1

THESTATISTICAL RESULTS OF BOTH GROUPS IN THEIR ENGLISH PROFICIENCY TEST

\begin{tabular}{|l|l|l|l|l|l|}
\hline Group & $\mathrm{N}$ & Mean & SD & T scores & P(level of significance for two-tailed test) \\
\hline E Group & 50 & 50.5541 & 5.50982 & -1.520 & 0.133 \\
\hline C Group & 50 & $52.6176 \quad$ & 5.93150 & & \\
\hline
\end{tabular}

\section{B. Research Instruments}

The research instruments include two vocabulary tests pre-oral-test, post-oral-test, reciting test and reciting report.

Vocabulary Test 1 is designed according to the new vocabularies in unit1and unit2. There are totally three parts: the first is 15 incomplete sentences, and the students are required to complete the sentences with one appropriate item chosen from the four choices. The total score is 30 . The second part is some frequently used expressions from text A of this unit, and the students are asked to translate them into correct Chinese. The score for this part is 40 . The third part is paragraph translation, and the students are required to translate a paragraph with the use of the expressions in this unit. The score for this part is 30 . The total score for vocabulary test 1 is 100 . This test was conducted in both the groups.

Vocabulary Test 2 is from the final exam paper. Two categories are included: the first is vocabulary choice (15 items and 15 scores), the second is 10 phrases translations (20 scores). The total score for this part is 35 .

The pre-oral-test was done at the beginning of the semester. The students were asked to present a speech in 3 minutes on the title "My First Impression on This College". The total score is 9, fluency, accuracy and complexity each 
accounting for 3 . The grades were given by five teachers by averaging the total scores of each student. The reference for the judges is based on Skehan's three-dimension evaluation of language production, Rod Ellis proposed measures on each aspect, which is displayed in the table 2.

TABLE 2

REFERENCE FOR ORAL TEST

\begin{tabular}{|l|l|}
\hline Dimensions & Measures \\
\hline 1. Fluency & Number of words per minute \\
& Number of pauses of one/two seconds or longer \\
& Mean length of pauses \\
& Number of repetitions \\
& Number of false starts \\
\hline 2. Accuracy & Number of self corrections \\
& Percentage of error-free clauses \\
& Target-like use of verb tenses \\
& Target-like use of articles \\
& Target-like use of vocabulary \\
& Target-like use of plurals \\
& Target-like use of negation \\
\hline 3.Complexity & Number of turns per minute \\
& Lexical richness. e.g. number of word families used. Percentage of lexical to structural words \\
& Percentage of occurrence of muti-prepositional utterances \\
& Amount of subordination, e.g. total number of clauses divided by total number of c-units \\
\hline
\end{tabular}

Post-oral- test was made in the end of the semester. The students were required to give a spontaneous speech on the topic "My English Learning" The spontaneous speech is conducted and evaluated the same as the pre-oral-test.

Finally is the Reciting Test. The content of the reciting is the selected paragraphs from the seven units of the textbook. Before the test, the teacher prepares seven small cards, on each of which the first sentence of one selected paragraph is offered. The students were required to recite according to the card. And the evaluation is based on the pronunciation, fluency and accuracy.

TABLE 3

RECITING ASSESSMENT TABLE

\begin{tabular}{|l|l|l|l|l|l|l|}
\hline \multirow{2}{*}{ Items } & \multicolumn{3}{|c|}{ Grade scales } & \multirow{2}{*}{ Grade } \\
\cline { 2 - 7 } & excellent & better & good & middle & poor & \\
\hline pronunciation(10 score) & 10 & 8 & 6 & 4 & 2 & \\
\hline Fluency (10 score) & 10 & 8 & 6 & 4 & 2 & \\
\hline Accuracy (10 score) & 10 & 8 & 6 & 4 & 2 & \\
\hline Total Score & \multicolumn{5}{l}{} \\
\hline
\end{tabular}

TABLE 4

A QUESTIONNAIRE

\begin{tabular}{|l|l|l|l|}
\hline Do you think reciting is relevant to the following statements & Very relevant & relevant & Not relevant \\
\hline Practice speech organs & & & \\
\hline Promote the use of new words and language chunks & & & \\
\hline Enhance language sense & & & \\
\hline Overcome negative transfer & & & \\
\hline Improve overall oral English level & & & \\
\hline
\end{tabular}

\section{Data Collection}

The data collection lasted for 16 weeks. They include two vocabulary tests, pre-oral-test, post-oral-test, reciting test and the questionnaire.

The vocabulary test 1 was conducted after the students have learned five units. It was asked to finish in 30 minutes. The teat 2 was done at the end of the semester in the final exam. The required time is 25 minutes. The results of the two tests are for statistical analysis.

The pre-oral-test was done in the first week of the semester, while the post-oral-test was at the end of the semester, and the duration between the two tests is 16 weeks. All the spoken language materials were transcribed.

Reciting Test was designed for the experimental group, and it was conducted in the last week of the semester. Each student was asked to recite about three minutes.

The questionnaire was carried out at the end of the experiment. The students of the experimental group were asked to fill in it carefully and the teacher collected, analyzed and categorized the reports so as to have a more thorough understanding of the students' attitudes towards reciting.

\section{Data Analysis}

The involved data in this research were analyzed with SPSS statistical method. The Independent-samples t-test was employed to compare the grades of the two groups to see if reciting is helpful to the use of new words, expressions and 
language chunks. At the same time, the correlation analysis was conducted to prove that the effect of reciting on the experimental group in both test 1 and test 2 were consistent. The analysis of the pre and post oral test was in two stages. In the first stage, the Chinglish expressions in the students' pre and post oral test were categorized and analyzed statistically, to find out if there were any differences between the two tests, so as to make sure that reciting input is helpful to reduce students' Chinglish expressions. In the second stage, the Independent-samples t-test was employed to compare the students' grade in the two oral tests to verify if reciting had a significant effect on improving students' overall oral English. What's more, correlation analysis was conducted to make certain that reciting and students' oral proficiency were relevant. In the end, the attitudes towards reciting of the students in the experimental group were studied with frequency statistics.

\section{E. Research Results and Discussions}

The independent-samples t-test showed that (see table 5 and table 6) the students of the two groups had significant difference in the grades of their two vocabulary tests. (It is respectively $\mathrm{T}=2.768, \mathrm{P}=0.007<0.05 ; \mathrm{T}=2.516$, $\mathrm{P}=0.014<0.05)$. The experimental group performed much better than the control group, which indicates that reciting was quite effective in promoting the use of vocabulary, and language chunks in students' oral output. This finding was in accordance with some previous researchers (Ding Yanren, etc. 2001; Dong Wei, etc. 2003). The major attributive factors for the differences between the two groups are the students of the experimental group have elevated their noticing attention to the specific words, fixed phrases and language chunks through reciting, which reinforces the language input, consolidates memory and facilitates vocabulary acquisition and application.

TABLE 5.

THE T-TEST RESULT FOR VOCABULARY TEST 1

\begin{tabular}{|l|l|l|l|l|l|}
\hline Group & $\mathrm{N}$ & Mean & SD & T values & P values (level of significance for two-tailed test) \\
\hline E Group & 50 & 78.3243 & 11.41163 & 2.768 & 0.007 \\
\hline C Group & 50 & 70.4118 & 12.67811 & & \\
\hline
\end{tabular}

TABLE 6.

THE T-TEST RESULT FOR VOCABULARY TEST2

\begin{tabular}{|l|l|l|l|l|l|}
\hline Group & $\mathrm{N}$ & Mean & SD & T values & P values (level of significance for two-tailed test) \\
\hline E Group & 50 & 19.5270 & 4.37472 & 2.516 & 0.014 \\
\hline C Group & 50 & 16.7206 & 5.02296 & & \\
\hline
\end{tabular}

The consistency effect of reciting on both vocabulary tests were tested by Pearson $r$. The result shows (table 7) a salient consistency. The Pearson $\mathrm{r}$ between the test 1 and the test 2 is 0.403 , and the $\mathrm{P}$ value is $0.013<0.05$. This shows that the reciting effect on the efficiency of language input is consistent in the two tests. In other words, if the experimental students perform better in test1, they would also do well in test2, though the tested vocabularies are from different units, which prove that the reciting effect will not change due to different time.

TABLE 7

THE CONSISTENCY EFFECT OF RECITING ON BOTH VOCABULARY TESTS

\begin{tabular}{|l|l|c|c|}
\hline \multicolumn{2}{|c|}{ Items } & Vocabulary test 1 & Vocabulary test 2 \\
\hline \multirow{5}{*}{ Vocabulary test 1} & Pearson $\mathrm{r}$ & 1 & 0.403 \\
\cline { 2 - 4 } & P values & 50 & 0.013 \\
\cline { 2 - 4 } & $\mathrm{N}$ & 0.403 & 50 \\
\hline \multirow{3}{*}{ Vocabulary test 2 } & Pearson $\mathrm{r}$ & 0.013 & 1 \\
\cline { 2 - 4 } & $\mathrm{P}$ values & 50 & 50 \\
\cline { 2 - 4 } & $\mathrm{N}$ & $* \mathrm{P}<0.05$ &. \\
\hline
\end{tabular}

The categorization and statistical analysis on the transcribed texts of the students' pre and post oral tests exhibited that an obvious difference exists between the two groups from the two tests (see table 8 and table 9 ). In the pre-test paper, the number and types of Chinglish expressions between the two groups are similar, with the control group a little lower in each item than the experimental group. After the experiment, the experimental group has reduced the number of Chinglish expressions in each of the three isolated categories as well as in the distribution of the total number, to be exact the reduced expressions are 154 in number. That indicates reciting is a high quality language input, which enlarges students' implicit language knowledge, thus reinforces students' language sense and greatly overcomes the negative transfer. As a result, students' overall oral English proficiency is improved. 
TABLE 8

STATISTICAL ANALYSIS ON CHINGLISH DISTRIBUTION IN PRE-ORAL-TEST

\begin{tabular}{|l|l|l|l|}
\hline Category & Number/percentage & E group & C group \\
\hline \multirow{2}{*}{ Literal translation } & number & 115 & 106 \\
\cline { 2 - 4 } & percentage & $28 \%$ & $27 \%$ \\
\hline \multirow{3}{*}{ Unmarked native expressions } & number & 60 & 55 \\
\cline { 2 - 4 } & percentage & $15 \%$ & $14.2 \%$ \\
\hline \multirow{2}{*}{ total } & number & 135 & 126 \\
\cline { 2 - 4 } & percentage & $42 \%$ & $40 \%$ \\
\cline { 2 - 4 } & number & 310 & 287 \\
\cline { 2 - 4 } & percentage & $100 \%$ & $100 \%$ \\
\hline
\end{tabular}

TABLE 9

STATISTICAL ANALYSIS ON CHINGLISH DISTRIBUTION IN POST-ORAL-TEST

\begin{tabular}{|l|l|l|l|}
\hline Category & Number/percentage & E group & C group \\
\hline \multirow{2}{*}{ Literal translation } & number & 43 & 89 \\
\cline { 2 - 4 } & percentage & $24 \%$ & $27 \%$ \\
\hline \multirow{2}{*}{ Unmarked native expressions } & number & 22 & 53 \\
\cline { 2 - 4 } & percentage & $12 \%$ & $16 \%$ \\
\hline \multirow{2}{*}{ others } & number & 114 & 191 \\
\cline { 2 - 4 } & percentage & $64 \%$ & $57 \%$ \\
\hline \multirow{2}{*}{ total } & number & 179 & 333 \\
\cline { 2 - 4 } & percentage & $100 \%$ & $100 \%$ \\
\hline
\end{tabular}

The pre oral test shows that the score distance between the total mean score of the two groups is only 0.16 , and the $\mathrm{P}$ values is $0.025<0.05$, which indicates that the two groups' English oral proficiency has no significant difference. After the experiment, the above mentioned two values are respectively 2.08 and $0.025<0.05$, which shows that reciting has caused a big difference in the oral performance of the two groups. The experimental group has accumulated a lot of vocabularies, grammar information and language chunks, which adds to the students' explicit knowledge in English. At the same time, with the increasing of reciting input, the students become more sensitive to the target language and their implicit knowledge is enlarged, which contributes to the reinforcement of students' language sense. Moreover, in the reciting process, the students can build a direct connection between the meaning of words and their pronunciation and sound, which ensures correct speech production and comprehension. The two parts are indispensable in normal speech production. Another fact is during the reciting process the students are rehearsing the real communication, which functions as both language input and output. We all know Chinese learners lack language environment, reciting is an ideal compensatory strategy. By doing this, the students become quick in oral production and comprehension. With consistent reciting practice, students can achieve an automatic level in their speech. Also, the reciting process helps to practice the students' speech organs, so they are ready to produce any sounds as quickly as possible. In one word, reciting promotes students' fluency, accuracy and complexity in their oral speech, which is shown clearly in the experiment (see table 10 and table 11).

TABLE 10.

PRE-ORAL-TEST DESCRIPTION

\begin{tabular}{|l|l|l|l|l|l|}
\hline Groups & $\mathrm{N}$ & MEAN & SD & T value & P value \\
\hline E group & 50 & 4.5000 & .80795 & & \multirow{2}{*}{} \\
\hline C group & 50 & 4.3382 & .92704 & .785 & .435 \\
\hline
\end{tabular}

TABLE 11

POST-ORAL-TEST DESCRIPTION

\begin{tabular}{|l|l|l|l|l|l|}
\hline Groups & $\mathrm{N}$ & Mean & SD & T value & P value \\
\hline E group & 50 & 6.8622 & .69775 & & \\
\cline { 1 - 3 } C group & 50 & 4.7794 & .70915 & 2.291 & .025 \\
\hline
\end{tabular}

As showed by table 12, the experimental group exhibits a clear positive correlation between the grades in reciting and post-oral-test. The Pearson $\mathrm{r}$ is 0.541 , and the $\mathrm{P}$ value is $0.001<0.01$. That indicates the reciting result and the post-oral result has statistical significance, and reciting has effective correlation to Chinese college English learners' oral English. The reason for this effect is as following: first, Chinese learners lack of sufficient English input, which makes it hard for the learners to achieve a fundamental improvement in their oral English. Second, the traditional teaching method is still prevailing and some new attempts prove to be unsuitable for Chinese learners due to various reasons. Most important of all, Chinese learners have no environment to produce output, which is critical for oral English. Reciting plays a role both in input and output. By paying noticing attention to the language material, the learners input quality is greatly enhanced. They focus both on linguistic structure and content, and they must be aware of the last details, such as the usage of the articles, prepositions and adverbs. Moreover, the reciting materials are sentences, paragraphs or a whole text, which is helpful for the students to master language in its ready made forms and in its proper contexts. With the 
accumulation of such ready made materials, learners can save much time and achieve greater fluency, accuracy and complexity to meet the needs of spontaneous speech.

TABLE 12

THE COEFFICIENT BETWEEN RECITING GRADE AND POST-ORAL-TEST GRADE

\begin{tabular}{|l|l|l|l|}
\hline \multicolumn{2}{|c|}{} & Reciting grade & Post-oral-test grade \\
\hline \multirow{5}{*}{ Reciting grade } & Pearson r & 1 & .541 \\
\cline { 2 - 4 } & P value &. & .001 \\
\cline { 2 - 4 } & $\mathrm{N}$ & 50 & 50 \\
\hline \multirow{2}{*}{$\begin{array}{l}\text { Post-oral-test } \\
\text { grade }\end{array}$} & Pearson $\mathrm{r}$ & .541 & 1 \\
\cline { 2 - 4 } & P value &. &. \\
\cline { 2 - 4 } & $\mathrm{N}$ & 50 & 50 \\
\hline
\end{tabular}

- significantly coefficient above 0.01

According to the feedback of the questionnaire from the experimental group (table13), most students hold positive attitudes towards reciting. They believe reciting increases the language input by remembering the language material in chunks, which can help to save the cognitive space and promote long term memory and can make the future retrieval easier and faster. In addition, during reciting the learners rehearse the speech process by fully involving the related speech organs, thus they find it easier to open their mouth and express themselves in English. With the accumulation of the language input and the readiness of expressing themselves, the learners' language sense has greatly improved and their implicit English knowledge has also increased, which is essential in reducing their Chinglish expressions. It is not surprising that the experimental group has done better than the control group in oral English performance. Actually, as is illustrated before, the effects of reciting is not confined to oral speech. It is beneficial to all aspects of English learning.

TABLE 13

FEEDBACK OF THE QUESTIONAIRE

\begin{tabular}{|c|c|c|c|c|c|c|}
\hline \multirow{2}{*}{$\begin{array}{l}\text { Do you think reciting is relevant to the } \\
\text { following statements }\end{array}$} & \multicolumn{2}{|c|}{ Very relevant } & \multicolumn{2}{|l|}{ relevant } & \multicolumn{2}{|c|}{ Not relevant } \\
\hline & frequency & percentage & frequency & percentage & frequency & percentage \\
\hline Practice speech organs & 48 & $96 \%$ & 2 & $4 \%$ & 0 & $0 \%$ \\
\hline $\begin{array}{l}\text { Promote the use of new 'words and } \\
\text { language chunks }\end{array}$ & 45 & $90 \%$ & 5 & $10 \%$ & 0 & $0 \%$ \\
\hline Enhance language sense & 40 & $80 \%$ & 8 & $16 \%$ & 2 & $4 \%$ \\
\hline Overcome negative transfer & 42 & $84 \%$ & 6 & $12 \%$ & 2 & $4 \%$ \\
\hline Improve overall oral English level & 46 & $92 \%$ & 4 & $18 \%$ & 0 & $0 \%$ \\
\hline
\end{tabular}

\section{CONCLUSIONS AND IMPLICATIONS}

\section{A. Implications}

This study aims to find if reciting is an effective method for Chinese college students to promote their oral output and make up for the shortage of English environment. The experimental findings exhibit a positive correlation between the two parts. Reciting has proved to be a quite facilitative way for Chinese college students to have a breakthrough in their oral English. It is an efficient and ideal language input. In quality, this input corresponds to Krashen's i +1 standard, since the reciting materials are all mostly from the textbook, which is carefully selected so as to match the college students' English proficiency, which has also been illustrated by the teacher in details to ensure complete comprehension. In quantity, this input is enough but not overwhelming. Enough does not refer to the number of the recited materials but the detailed processing of the material. Students are required to recite some selected sentences or paragraphs of the learned texts, which does not take too much time and energy. Since it is easy to implement, after completing the task and applying the recited contents in their own English expression, students tend to gain a sense of fulfillment and develop confidence in English learning. Meanwhile, reciting is also a kind of oral output. Though this output is closely adhered to the written language material, it contains some common features of the real oral English output. First of all, it involves the participation of the speech organs, otherwise learners usually find themselves tongue-tied in real speech circumstance, because their speech organs have been accustomed to the Chinese pronunciation and without practice it is hard for them to meet the needs of real communication. Secondly, as Swain has claimed output forces the students to notice the gap between what they want to say and what they can say. The reciting process offers this chance and the reciting materials tell the learners what they should say and thus bridge the gap between their expressions and the proper expressions. This helps to build up the learners' language sense or we call it implicit language knowledge. Lastly, the reciting styles can be various and interesting, for example by playing roles, seeing films or performing programs. As the experiment has showed reciting is really helpful for Chinese college students to improve their oral English. It should be promoted and widely applied.

\section{B. Limitations of the Study}

Due to various reasons, this study has three major limitations. First, the experimental duration is not long enough, so some expected results can not be fully demonstrated. In other words, the far reaching effects from reciting can hardly be 
tested. Second, it is obvious that many factors may contribute to the change in one's learning. During this experiment, the other variables have been controlled to the minimal degree, but still some factors are beyond this subjective control, for example, learner's emotions, attitudes, and adaptability to the new environment and learning strategies. The biggest problem exists in the experimental instruments. In an ideal oral test record, the subjects' oral presentation should be recorded and analyzed in details. Nevertheless, in this study due to the limited time and energy, the general evaluation was conducted by five judges according to the given assessing references. Therefore, subjectivity is inevitable and it may influence the overall validity and reliability of the experiment.

\section{Suggestions for Future Study}

If researchers conduct studies in this area, the following suggestions can be of their reference. First, the duration of the research should be at least one year or if possible for two years. Since college students have two years' formal English class learning, it will be convenient for this study. The findings from two years' research are more convincing and scientific and the expected results can be more obvious. Second, the modern language lab should be applied to the recording and analysis of the oral speech. That will attribute to the accuracy of the results in the experiment and achieve high validity and reliability. Lastly, the researchers can vary the reciting styles and materials. For the reciting styles, the subjects can have more options, for example, they can relate the main idea of the target materials by using as many original expressions as possible; or they can remember the materials by role playing. As for the reciting materials, apart from the passages from the textbook, some other more interesting materials can be of their choice, such as cartoons or films. In a word, it is of great help if students can find pleasure in this practice and they can assume it as a learning habit. Therefore, a fundamental task for the researchers in this area is to develop a helpful method to guarantee its consistent practice and ensure its maximum facilitation in oral proficiency.

\section{REFERENCES}

[1] Anderson, J. R. (1982). Toward an instance theory of automatization. Psychological Review, 95, pp. 492-527.

[2] Bachman, L.F., \& Palmer, A. S. (1996). Language testing in practice. Shanghai: Foreign Language Education Press.

[3] Brumfit, C. (1984). Communicative methodology in language teaching. Cambridge: Cambridge University Press.

[4] Cohen, D. A. (2000). Strategies in learning and using a second language. Beijing: Foreign Language Teaching and Research Press.

[5] Craik, F. I. M. \& Tulving, E. (1975). Depth of processing and the retention of words in episodic memory. Journal of Experimental Psychology: General, 104, pp. 268-294.

[6] Cruttenden, A. (2001). Gimson's pronunciation of English (6th ed.). Beijing: Foreign Language Teaching and Research Press.

[7] Dell, G. S. (1985). Positive feedback in hierarchical connectionist models: Applications to language production. Cognitive Science, 9, pp. 3-23.

[8] Ellis, R. (1985). Understanding second language acquisition. Oxford: Oxford University Press.

[9] Garrett, M. F. (1988). Processes in Language Production. In F. J. Newmeyer (Ed.), Linguistics: The Cambridge Survey (pp. 69-96). Cambridge: Cambridge University Press.

[10] Hamayan, E. \& R. Tucker. (1980). Language input in the bilingual classroom and its relations to second language achievement. TESOL Quarterly 14: pp. 453-68.

[11] Hatch, E. \& J. Wagner-Gough. (1976). Explaining sequence and variation in second language acquisition. Language Learning, Special Issue 4: pp. 39-47.

[12] Hunt, R. R. \& H. C. Ellis. (2006). Fundamentals of Cognitive Psychology. Beijing: Posts \& Telecom Press.

[13] Krashen, S. D. (1981). Second language acquisition and second language learning. Oxford: Pergamon

[14] Krashen, S. D. (1985). The input hypothesis: Issues and implications London: Longman.

[15] Krashen, Stephen D. (1987). Principles and Practice in Second Language Acquisition. Prentice-Hall International.

[16] Larsen-Freeman, D. (1976). Teacher speech as input to the ESL learner. University of California. Working Papers in TESL 10: 45-49.

[17] Levelt, W. J. M. (1989). Speaking: From intention to articulation. Cambridge: MAMIT press.

Xiao Liu was born in Baotou, inner Mongolia, in1976. She got Master's degree of Art at Foreign Languages College, Inner Mongolia University, Huhhot, in 2008.

She is working as a lecturer in Foreign Languages department of Inner Mongolia Finance and Economics College, Huhhot, P.R. China, teaching English Literature. 